\title{
LA MODERNIZACIÓN DE LA EXPLOTACIÓN AGRARIA EN CASTILLA Y LEÓN: EMPRESARIOS AGRARIOS Y PROPIETARIOS AGRÍCOLAS
}

\author{
F. Molinero Hernando, E. Baraja Rodríguez y D. Herrero Luque \\ Universidad de Valladolid
}

\section{RESUMEN}

La disponibilidad de abundante información estadística, en contra de lo que suele suceder, nos ha permitido establecer unas hipótesis de trabajo sugerentes, generalmente no contempladas en los planteamientos habituales de los políticos y ordenadores del territorio, sobre el mundo agrario y rural de Castilla y León.

De hecho, la agricultura durante el siglo XxI ha continuado su paso inexorable hacia la modernización, tecnificación e inserción en el mercado global, lo que ha producido una disminución radical del número de explotaciones y una profesionalización de las que se han mantenido. Y, aunque estos hechos pueden parecer una crisis agraria, y así se interpretan a menudo, no lo son, salvo en determinadas ramas, por cuanto la crisis agraria acabó hace más de un decenio. Hoy, por el contrario, asistimos a una modernización de la que forman parte dos tipos de agricultores: los empresarios y los restantes, entre los que se incluye un nutrido grupo de propietarios, de poco significado económico, y un creciente número de Agricultores a Tiempo Parcial, que complementan a los empresarios.

Palabras clave: modernización, profesionalización, explotación agraria, Castilla y León

\section{ABSTRACT}

The modernization of agrarian holdings in Castille and Leon: between agrarian entrepreneurs and landowners

The availability of abundant statistical information, contrary to what normally happens, has allowed us to establish a suggestive work hypothesis, usually not considered in the approaches of politicians and experts on land use and territorial management of the agricultural and rural world of Castile and Leon.

In fact, during the XXI century agriculture has continued its inexorable path towards modernization and integration into global markets, which has produced a radical 
reduction in the number of farms and a professionalization and entrepreneurial management of those who have remained. And while these events may seem an agrarian crisis, and thus are often interpreted, they are not, except in certain branches (milk...), as the agrarian crisis ended more than a decade ago. Today, however, we are witnessing a modernization which includes two types of farmers, the entrepreneurs and the rest, including a large group of owners of little economic significance, and an increasing number of Part Time Farmers, complementary to entrepreneurs.

Keywords: modernization, professionalization, agrarian holdings, Castille and Leon.

\section{LA INEXORABLE MODERNIZACIÓN DE LA EXPLOTACIÓN AGRARIA: FUENTES, MÉTODO E HIPÓTESIS DE TRABAJO}

La coincidencia temporal de varias fuentes estadísticas nos ha permitido comprobar los rasgos estructurales más llamativos de las explotaciones agrarias en Castilla y León, donde ni el carácter extensivo predominante, ni la fragmentación de la propiedad agraria tradicional, han oscurecido los rasgos de las nuevas explotaciones, cada vez más agrandadas, tecnificadas y competitivas, empujadas por el mercado global, que obliga a los agricultores europeos a competir en él, por más que el paraguas de la PAC los esté protegiendo contra contingencias y aleatoriedades. Y no es baladí el plantearse estas cuestiones, pues la explotación agraria es la célula básica del campo, la que organiza el espacio agrario y, en gran medida, el rural.

De ahí que la publicación del Censo Agrario 2009 (dado a conocer por el INE, en microdatos, en 2012), junto a la nueva publicación de los Pagos PAC por el FEGA, y la disponibilidad de los cotizantes a la Seguridad Social a escala de municipios para diversos años, han constituido bases de análisis de gran solidez para conocer y confirmar la marcha de la explotación agraria en nuestro ámbito de estudio.

\section{La abundancia de fuentes a escala municipal y su valor socioterritorial}

En la era de Internet y, al amparo de la Ley de Transparencia de las Administraciones Públicas, los investigadores estamos recibiendo gran cantidad de bases de datos, que, tratadas adecuadamente y con criterio, informan claramente de la evolución de los fenómenos agrarios a distintas escalas.

Es el caso, en primer lugar, del Censo Agrario de 2009, que, aunque hecho público en 2012 a escala de explotación, da una idea clara de la dinámica agraria en nuestro país. Es una fuente completa, si bien la fragmentación de explotaciones dentro del matrimonio o de la familia, o el registro de explotaciones marginales de jubilados, encubre el verdadero tamaño de la explotación funcional. 
En segundo lugar, el Fondo Español de Garantía Agraria, que desde 2006 viene publicando los Pagos PAC, ofrece una ayuda inestimable, con identificación personal de sus perceptores y, a pesar de que en 2009 interrumpió la serie por protestas de los agricultores alemanes, la ha vuelto a poner en marcha, proporcionando una información extraordinaria, para conocer quién es quién en la agricultura española. Las últimas estadísticas se refieren al año 2014. El valor de estos datos es desigual, ya que aquí figuran principalmente «propietarios» que reciben Pagos PAC, aunque en los casos de los Agricultores a Título Principal suelen coincidir propietario y explotador, si bien es cierto que hay una cuarta parte de perceptores de pagos PAC que reciben menos de $1.250 € /$ año, los cuales tienen muy poca entidad como productores agrarios, por más que engorden las estadísticas del Censo y de los Padrones de Pago Único o Pago Básico de la PAC.

En tercer lugar, hemos contado con una fuente de excepcional valor, controlada y regida por la Tesorería General de la Seguridad Social, que, trimestralmente, da cuenta del número de cotizantes, es decir, de personas ocupadas, en las distintas ramas económicas, según la Clasificación Nacional de Actividades Económicas, a escala municipal. La comparación y, en la medida de lo posible, el cruce de las tres fuentes, permite realizar una foto del estado y dinámica de las explotaciones agrarias en Castilla y León, y en España, que nos habla de su incidencia en las estructuras agrarias regionales y nacionales, y nos muestra la composición de su tejido agrario.

\section{La dinámica menguante del campo castellano-leonés en el contexto español}

Los agricultores, y los empleados agrarios en general, están reduciéndose en número. Y, aunque a menudo se plantea, desde la política o el sindicalismo agrario, la necesidad de rejuvenecer y recuperar el campo, no se puede ir a contracorriente del sentido de la historia, cuya tendencia es crear explotaciones suficientes en número y en tamaño, pero no a crear empleo agrario, que, como veremos, excede las posibilidades que el campo tiene. Y es por ahí por donde van los hechos. Así, Maté valora las estadísticas del INE diciendo que la población activa agraria de España habría pasado de unos 2,2 millones en 1985 (menos del $20 \%$ de la total, justo antes de entrar en la CEE) a 992.000 en 2015 (algo más del 4\%) mientras los ocupados pasaron de dos millones a 750.000 , en tanto que los perceptores de ayudas PAC alcanzan los 900.000, si bien extraoficialmente se baraja una cifra real de unos 350.000 agricultores y ganaderos funcionales, con una entidad considerable de los agricultores a tiempo parcial. Estos datos nacionales nos ayudan a comprender los regionales (Maté, V., 2015).

Así lo podemos comprobar en una primera aproximación: tanto el análisis de los dos últimos censos agrarios como el más reciente de cotizantes a la 
Seguridad Social, en el régimen agrario, evidencian una reducción sensible de los titulares de explotaciones, (1999 a 2009), así como de los ocupados durante los años de la crisis, desde 2007 a 2015. Y, aunque en otras ramas ha incidido la crisis con mucha más fuerza que en esta, no cabe duda que la reducción es tendencial, estructural, por más que, puntualmente aparezcan focos de creación de empleo agrario, como ha sucedido en las comarcas hortícolas del Carracillo, en las vitícolas de La Ribera del Duero, o en algún otro municipio concreto y de poca entidad, como veremos.

\section{REDIMENSIONAMIENTO, REDUCCIÓN DEL EMPLEO Y CONSOLIDACIÓN DE UNA AGRICULTURA CAPITALISTA Y EMPRESARIAL}

Por más que los políticos y ordenadores del territorio se empeñen en hacer planes para recuperar el campo y para crear empleo en la agricultura, mediante la Agenda 2000 o mediante Planes de Desarrollo Regional, los datos son incontestables: el número de explotaciones agrarias está cayendo, el número de agricultores autónomos y asalariados está perdiendo entidad igualmente, y, al contrario, la potencia técnica y el tamaño económico de las explotaciones agrarias se está consolidando y afirmando. Y no se trata de una mera cuestión de números, ni de un mero análisis de variables agronómicas, por cuanto la agricultura y los agricultores constituyen la trama fundamental del espacio rural en regiones como Castilla y León, en las que todavía una mayoría de municipios viven esencialmente de la agricultura y donde los Pagos PAC integran, en gran medida, una parte sustancial de las ayudas que se dan al desarrollo rural.

\section{La caída del número de las explotaciones censales y la estructura de las funcionales}

Si partimos de la base de que la agricultura dominante en Castilla y León es extensiva y de que las explotaciones son todavía demasiado pequeñas para competir en el mercado global, comprobaremos que la tendencia a la reducción obedece esencialmente a esa circunstancia, que obliga a los titulares que se retiran a ceder sus tierras o ganado a agricultores que lo gestionan en arrendamiento, a veces en aparcería y, por lo general, hacen las labores de los propietarios, quienes continúan figurando como titulares y cobrando los pagos PAC, mientras el «agricultor» recibe el canon estipulado por el trabajo realizado. Así, al tiempo que decrece el número de agricultores y que aumenta el tamaño de las explotaciones, se mantiene un elevadísimo número de perceptores de Pagos PAC, que excede con creces el número de explotaciones funcionales. Una buena parte de este tipo de agricultor lo es a Tiempo Parcial, favorecido por la PAC, así como por el hecho de que hay numerosos jubilados que continúan «llevando» su explotación, aunque no sean titulares de ella. Por ello, en una primera aproximación, 
debemos valorar las estadísticas de los dos últimos censos agrarios (1999 y 2009), para compararlos después con los perceptores de ayudas PAC y otros datos relevantes, cuyos resultados presentamos en los cuadros 1 y 2 .

Cuadro 1. Estructura de las explotaciones agrarias de Castilla y León en 1999 y 2009

\begin{tabular}{|c|c|c|c|c|c|c|}
\hline $\begin{array}{l}\text { CENSO AGRARIO } \\
2009\end{array}$ & $\begin{array}{c}\text { N. }{ }^{\circ} \text { de } \\
\text { explotaciones }\end{array}$ & $\%$ del n. ${ }^{\circ}$ & $\begin{array}{l}\text { Superficie } \\
\text { total (ha) }\end{array}$ & $\begin{array}{c}\% \text { de } \\
\text { superficie } \\
\text { total }\end{array}$ & $\begin{array}{l}\text { Superficie } \\
\text { SAU (ha) }\end{array}$ & $\%$ de SAU \\
\hline Todas las explotaciones & 98.247 & 100 & 6.683 .954 & 100 & 5.362 .468 & 100 \\
\hline Explotaciones con tierras & 95.248 & 100 & 6.683 .954 & 100 & 5.362 .468 & 100 \\
\hline Explotaciones sin SAU & 479 & 0,5 & 6.463 & 0,1 & 0 & 0 \\
\hline Explotaciones con SAU & 94.769 & 99,5 & 6.677 .491 & 99,9 & 5.362 .468 & 100 \\
\hline$<1$ ha & 1.662 & 1,7 & 14.398 & 0,2 & 595 & 0 \\
\hline $1 \mathrm{a}<2$ ha & 8.873 & 9,3 & 108.225 & 1,6 & 11.618 & 0,2 \\
\hline $2 \mathrm{a}<5$ ha & 11.970 & 12,6 & 72.803 & 1,1 & 38.289 & 0,7 \\
\hline $5 \mathrm{a}<10$ ha & 10.365 & 10,9 & 100.197 & 1,5 & 73.902 & 1,4 \\
\hline $10 \mathrm{a}<20$ ha & 12.283 & 12,9 & 234.706 & 3,5 & 176.817 & 3,3 \\
\hline $20 \mathrm{a}<30$ ha & 8.591 & 9 & 249.984 & 3,7 & 211.290 & 3,9 \\
\hline $30 \mathrm{a}<50$ ha & 11.686 & 12,3 & 522.502 & 7,8 & 453.705 & 8,5 \\
\hline $50 \mathrm{a}<100$ ha & 14.200 & 14,9 & 1.156 .330 & 17,3 & 1.010 .880 & 18,9 \\
\hline$>=100$ ha & 15.139 & 15,9 & 4.218 .346 & 63,1 & 3.385 .372 & 63,1 \\
\hline
\end{tabular}

\begin{tabular}{|l|c|r|r|r|r|r|}
\hline $\begin{array}{l}\text { CENSO AGRARIO } \\
\mathbf{1 9 9 9}\end{array}$ & $\begin{array}{c}\text { N. }{ }^{\circ} \text { de } \\
\text { explotaciones }\end{array}$ & \% del n..$^{\circ}$ & $\begin{array}{c}\text { Superficie } \\
\text { total (ha) }\end{array}$ & $\begin{array}{c}\text { \% de } \\
\text { superficie } \\
\text { total }\end{array}$ & $\begin{array}{c}\text { Superficie } \\
\text { SAU (ha) }\end{array}$ & \% de SAU \\
\hline Todas las explotaciones & 175.454 & 100 & 8.150 .108 & 100 & 5.783 .831 & 100 \\
\hline Explotaciones sin tierras & 5.892 & 3,4 & 0 & 0 & 0 & 0 \\
\hline Explotaciones con tierras & 169.562 & 96,6 & 8.150 .108 & 100 & 5.783 .831 & 100 \\
\hline$<1$ ha & 26.440 & 15,6 & 12.830 & 0,2 & 7.988 & 0,1 \\
\hline $1 \mathrm{a}<2$ ha & 17.471 & 10,3 & 24.582 & 0,3 & 13.875 & 0,2 \\
\hline $2 \mathrm{a}<5$ ha & 26.445 & 15,6 & 84.918 & 1,0 & 51.182 & 0,9 \\
\hline $5 \mathrm{a}<10$ ha & 20.016 & 11,8 & 142.801 & 1,8 & 102.135 & 1,8 \\
\hline $10 \mathrm{a}<20$ ha & 20.416 & 12,0 & 292.769 & 3,6 & 245.978 & 4,3 \\
\hline $20 \mathrm{a}<30$ ha & 12.175 & 7,2 & 298.457 & 3,7 & 269.566 & 4,7 \\
\hline $30 \mathrm{a}<50$ ha & 14.611 & 8,6 & 565.020 & 6,9 & 526.443 & 9,1 \\
\hline $50 \mathrm{a}<100$ ha & 15.954 & 9,4 & 1.123 .975 & 13,8 & 1.055 .377 & 18,2 \\
\hline$>=100$ ha & 16.032 & 9,5 & 5.604 .754 & 68,8 & 3.511 .286 & 60,7 \\
\hline
\end{tabular}

Fuente: INE: Censo Agrario 1999 y Censo Agrario 2009 (Apud Molinero, F., 2012, p. 448). 
Es llamativo que la superficie media de las explotaciones regionales no alcance más que 56,6 ha SAU (en 2009), a todas luces insuficientes para una agricultura extensiva, pero lo es mucho más que un tercio de ellas, con menos de 10 ha, tan solo cuentan con 3,8 ha de superficie media. Es evidente que en este tercio de la base solo caben explotaciones a Tiempo Parcial, además de un nutrido colectivo de jubilados y de un pequeño grupo de horticultores y ganaderos intensivos, pero no es este precisamente el carácter esencial de la explotación agraria del Duero. Ahora bien, si nos fijamos en lo que sucedía diez años antes, comprenderemos que la evolución ha sido radical, ya que tanto la superficie media general como la correspondiente al grupo de las más pequeñas, se han casi duplicado, en tanto que las medianas y grandes han crecido relativamente poco, aspectos relacionados claramente con la desaparición de numerosos titulares de explotación, que no eran agricultores, sino meros propietarios, muchos de ellos jubilados, que acaban cediendo sus tierras a otros agricultores o gestores.

Tanto las estadísticas censales como las de cotizantes a la Seguridad Social, o las de perceptores de ayudas de la PAC, aportan unos resultados congruentes, aunque con pequeñas diferencias. En todos los casos nos aproximamos a unos 100.000 agricultores, que van cayendo desde las 169.562 explotaciones con tierras declaradas en el Censo de 1999, a las 95.248 del de 2009, o los 104.000 perceptores de Pagos PAC de ese mismo año, y que una parte sustancial de ellos -el 40\% aproximadamente- lo son a Título Principal, como ya demostramos (Molinero, F., 2012: 447 y 448). Estos son los que mantienen el tejido social del rural profundo, de los municipios más pequeños, que están más agrarizados. Su número no deja de caer, porque aún no son lo suficientemente competitivos en un mercado abierto y globalizado. La dimensión media de estas explotaciones no resulta razonable para una empresa moderna, ni es tampoco congruente con las cantidades de ayudas PAC que perciben, pero todo ello concuerda si partimos de esa cifra que maneja el Ministerio de Agricultura y los expertos (como V. Maté, entre otros), de que solo el $40 \%$ son las verdaderas explotaciones funcionales, y éstas son las que reciben la mayor parte de las ayudas PAC, porque son precisamente las que controlan más del $80 \%$ de la Producción Estándar Total (PET), de la tierra, del ganado y de los Pagos PAC.

Así, vemos que las explotaciones mayores de 50 ha controlaban el $79 \%$ de la SAU en 1999 y hasta el 82\% diez años más tarde. Por el contrario, las explotaciones que podríamos considerar medianas, de entre 20 a 30 y 50 ha, han perdido peso en el conjunto, pasando de 13,8 a $12,4 \%$ de la SAU, porque tienden a crecer en tamaño, por un lado, y a desaparecer, por otro, como bien se aprecia entre las dos fechas censales, en las que se pierde un tercio de las comprendidas en esos rangos, aunque también las más grandes se reducen en 
número, pero mucho menos; así, las de $>30$ ha solo pierden un $10 \%$ del número. Es evidente que el camino es hacerse menos numerosas y más grandes.

Frente a ellas, las pequeñas, pierden igualmente número y peso, porque no pueden sobrevivir. Como se observa en la figura 1, la desaparición de las

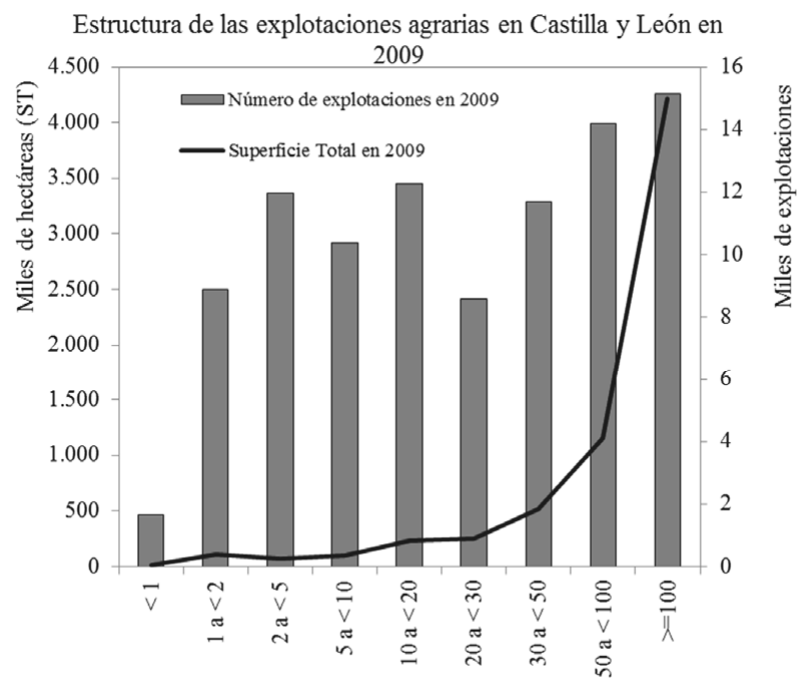

Rangos, por tamaño de la explotación, en hectáreas

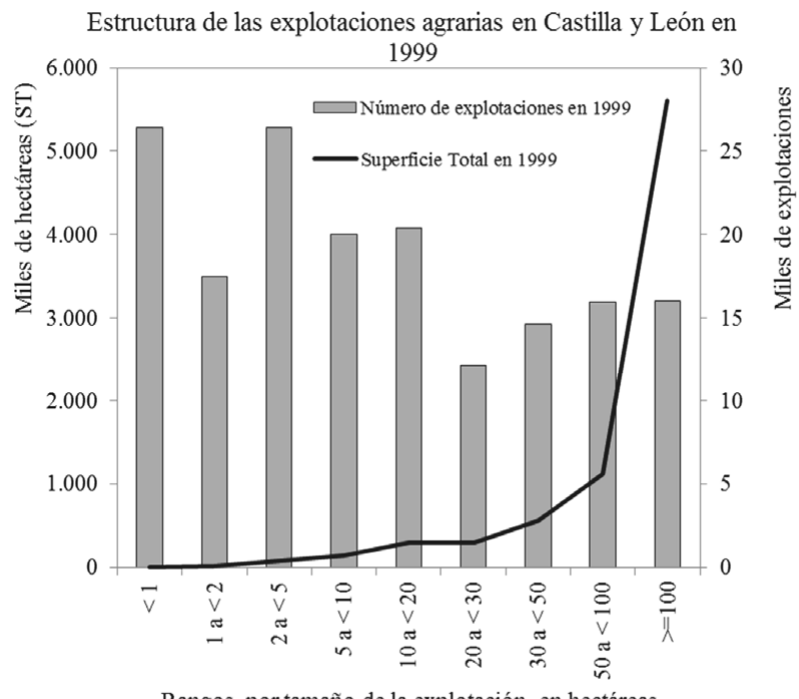

Rangos, por tamaño de la explotación, en hectáreas

Figura 1. Evolución y estructura de las explotaciones agrarias en Castilla y León entre 1999 y 2009. 
explotaciones más pequeñas entre 1999 y 2009 es una realidad, que no se ve compensada por el incremento de las medianas sino tan solo de las grandes. No obstante, el control de la Superficie Agrícola Utilizada es muy similar en ambas fechas, porque la profesionalización de los agricultores se produjo desde hace más de tres decenios. Por ello, tan solo aparecen matices entre ambas fechas, que se derivan del agrandamiento de la explotación agraria por arriba, mientras que por abajo, desaparecen numerosas explotaciones estadísticas, no funcionales, que, dado que no necesitan comercializar productos agrarios, tampoco aparecen censadas, aunque sí figuren como perceptores de pagos PAC, para lo que no necesitan requisitos especiales.

Como resultado final, las más de 175.000 explotaciones de 1999, han caído a poco más de 98.000 , incluidas las «sin tierra», que casi coinciden con los perceptores de ayudas PAC en ese mismo año. Así, si observamos el cuadro 2 y la figura 2, comprobamos que hay casi 105.000 perceptores de ayudas PAC, que se distribuyen con cierta homogeneidad por todo el territorio regional, si bien llama la atención el que las áreas de montaña, las menos favorecidas, son las que menos pagos reciben. Y esta circunstancia no es baladí, pues, en teoría, las distintas ayudas a los agricultores y ganaderos europeos pretendían fijar la población rural para mantener los servicios y contribuir, así, a su bienestar y desarrollo. Es lo que se afirmaba en 1975 en la Directiva 75/268/EEC sobre

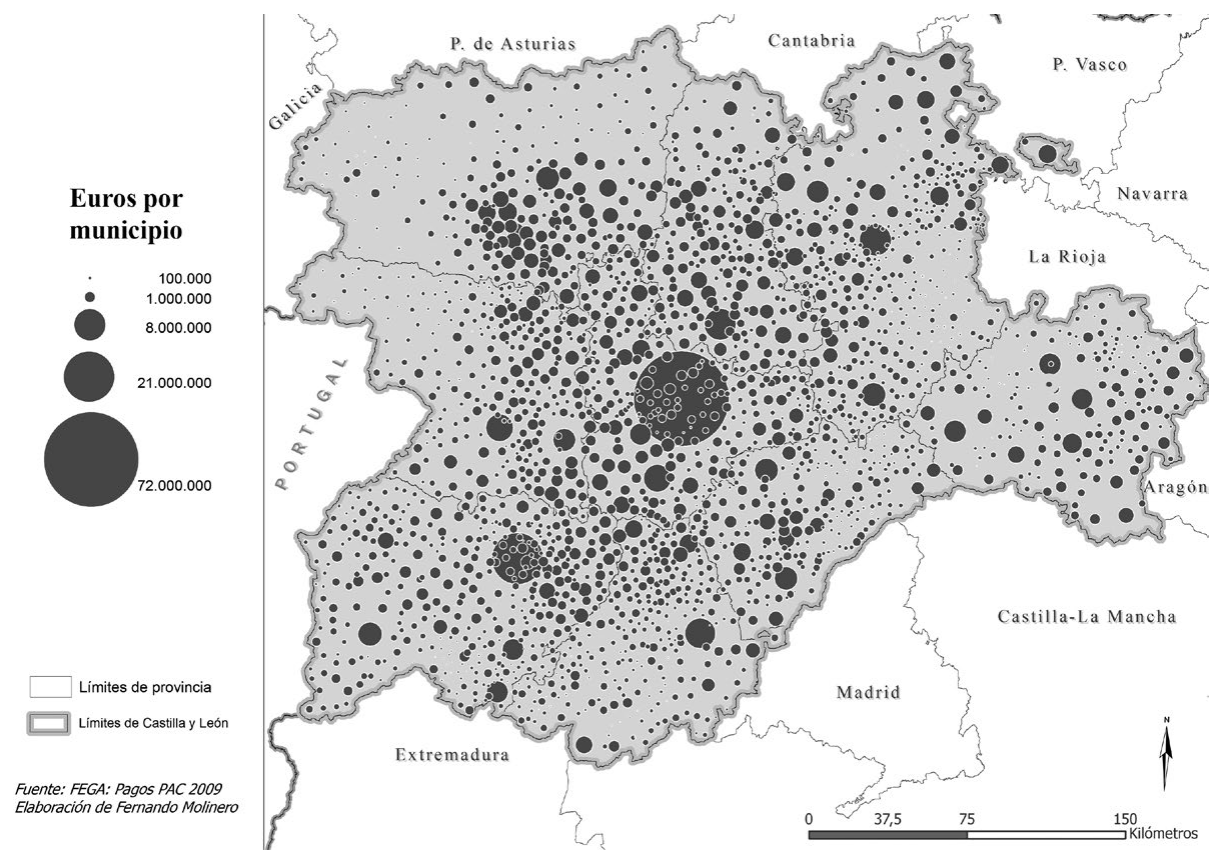

Figura 2. Distribución municipal de los pagos PAC en Castilla y León en 2009. 
Cuadro 2. Distribución de los Pagos PAC y de variables agrarias fundamentales por tamaño de municipio en Castilla y León en 2009

\begin{tabular}{|c|c|c|c|c|c|c|c|c|c|}
\hline 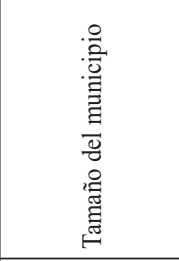 & 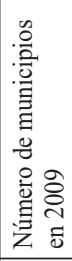 & 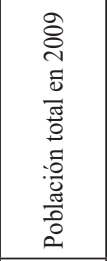 & 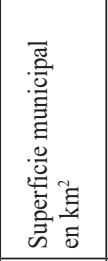 & 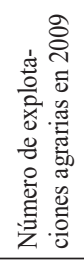 & 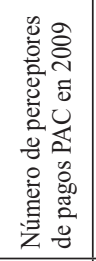 & 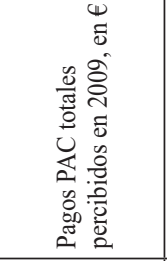 & 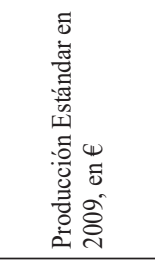 & 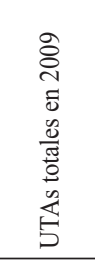 & 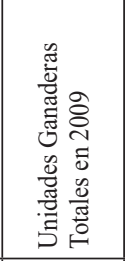 \\
\hline$<2.000 \mathrm{hb}$ & 2.115 & 677.282 & $81.145,3$ & 82.692 & 77.622 & $885.934 .794,1$ & 3.502 .529 .199 & $60.205,5$ & $1.884 .775,4$ \\
\hline $2.000 \mathrm{a}<5.000$ & 76 & 232.450 & $6.653,7$ & 8.130 & 8.123 & $75.900 .569,8$ & 354.034 .696 & $5.816,5$ & $205.572,4$ \\
\hline $5.000 \mathrm{a}<10.000$ & 32 & 214.481 & $3.492,4$ & 4.128 & 5.454 & $52.430 .800,9$ & 192.566 .687 & $3.379,9$ & 98.809, \\
\hline $10.000 \mathrm{a}<20.000$ & 10 & 135.431 & 764,0 & 823 & 1.516 & $15.668 .593,5$ & 23.435 .908 & 609,8 & $22.089,0$ \\
\hline $20.000 \mathrm{a}<50.000$ & 6 & 185.928 & 746,1 & 801 & 1.917 & $18.201 .864,6$ & 37.948 .190 & 704,6 & $14.660,0$ \\
\hline 50.000 y más & 9 & 1.117 .949 & $1.314,4$ & 1.673 & 10.299 & $131.885 .748,4$ & 49.964 .867 & $1.115,3$ & $29.061,9$ \\
\hline Total general & 2.248 & 2.563 .521 & \begin{tabular}{|l|}
$94.115,9$ \\
\end{tabular} & 98.247 & 104.931 & $1.180 .022 .371,3$ & 4.160 .479 .547 & $71.831,5$ & $2.254 .968,6$ \\
\hline
\end{tabular}

Fuente: INE: Censo Agrario 2009 y Padrón de Habitantes 2009; FEGA: Pagos de la PAC 2009 para todas y cada una de las explotaciones de España, en www.fega.es. Consulta de febrero de 2010 (Apud Molinero, Herrero y Baraja (2012): «Significado y valor de los pagos «PAC» para el estudio de las estructuras agrarias en Castilla y León», Nimbus, n. . 29-30, pp. 431-446).

Zonas de Agricultura de Montaña, lo mismo que en las Directivas 75/269 y 75/276/EEC para la promoción del turismo y la artesanía rural. Sin embargo, las dificultades inherentes a la montaña, por su alejamiento, aislamiento y menor integración, han abocado a una situación en la que la densidad de población ha caído a mínimos históricos, lo mismo que ha sucedido con las explotaciones agrícolas y ganaderas, en contra de los objetivos perseguidos por la Comisión Europea, por más que, desde la perspectiva de la diversificación económica, se han conseguido aparentemente.

En efecto, las áreas de montaña de la región son las más diversificadas, pero con muy pocos activos en todas las ramas. En la Cordillera Cantábrica, en los Montes de León y en la Cordillera Ibérica el vacío agrario ha abocado a un vacío demográfico, pero quienes han permanecido en estas tierras han recrecido considerablemente su cabaña ganadera, especialmente de vacuno de carne, que es el aprovechamiento más extendido. Los pocos ganaderos que quedan han aprovechado las ayudas para construir naves modernas, para comprar maquinaria, para tecnificar el ensilado de la hierba en paquetes de plástico... Solo en la Cordillera Central ha resistido un mayor número de explotaciones, por la demanda de carne de calidad del mercado madrileño. En las llanuras centrales, por otro lado, las ayudas PAC se distribuyen más homogéneamente, con la excepción de la las ciudades, hinchadas de agricultores titulares de explotación agraria, pero que viven en la urbe, pues, tal como se observa en el cuadro 2, la 
mayor parte de los profesionales agrarios habita en el campo, pero en los nueve municipios más grandes de la región vive un $10 \%$ de los perceptores de ayudas PAC, que, obviamente, no ejercen la actividad agraria en ellos.

En el cuadro puede verse que el número de explotaciones agrarias y el de perceptores corren parejos. Si en los Pagos PAC de 2009 figuraban casi 105.000 perceptores, el Censo Agrario de ese año recogía 98.247 explotaciones. Sin embargo, los empleados cotizantes a la Seguridad Social en 2007 no llegaban más que a 71.556. Esto quiere decir que el empleo real en la agricultura estaba en torno al valor más bajo, por las razones ya comentadas. Es evidente que todo aquel que trabaja en la agricultura se da de alta en la Seguridad Social y, en este caso, tan solo se registran los 71.556 ocupados en 2007, que se reducen incluso a 60.637 en 2014 (cfr. cuadro 3). Esta última cifra constituye la referencia válida más actualizada, pues, como decíamos en la introducción para el caso de España, la reducción intercensal del número de explotaciones no refleja la situación funcional ni en España ni en Castilla y León u otras regiones.

\section{Una caída constante del empleo agrario}

Basta con observar el mapa (figura 3) para comprobar la magnitud y persistencia de las pérdidas de empleo agrario. En efecto, en el conjunto del campo castellano-leonés, durante los ocho años de crisis, se han perdido 11.146 empleos netos, por más que en tres centenares de municipios se hayan ganado 361. En principio, parece contradictorio con los planteamientos generales, ya que el campo siempre se ha visto como un sector refugio frente a la crisis; de ahí que sea más llamativo el haber perdido esos más de diez mil cotizantes a la Seguridad Social, partiendo del hecho de que los «cotizantes» son los agricultores y asalariados agrarios funcionales.

$\mathrm{Y}$ es que, en contra de un sentir general urbano, el campo del interior de España, y especialmente el de Castilla y León, forma parte del rural profundo, caracterizado por todos los aspectos negativos típicos: una baja densidad de población ( $12 \mathrm{~h} / \mathrm{km}^{2}$ de media en los 2.193 municipios rurales regionales) (Alario Trigueros et al, 2014: 401), una dinámica demográfica regresiva, un envejecimiento generalizado, una escasa diversificación económica... Y estos rasgos negativos conducen a que sea la actividad agraria la protagonista del mundo rural, por más que en las montañas circundantes, especialmente en la Cordillera Central y en la Cantábrica, otras ocupaciones económicas superen a la agraria, pero más por caída drástica de esta que por aumento de aquellas.

Es llamativo, en este sentido, el que las áreas de menores pérdidas de ocupados se localicen en las montañas del norte y oeste de la región, que es donde menos población reside, porque ya acabaron hace tiempo los procesos de éxodo rural y de modernización. De ahí que tan solo quedan unos pocos ganaderos, que 


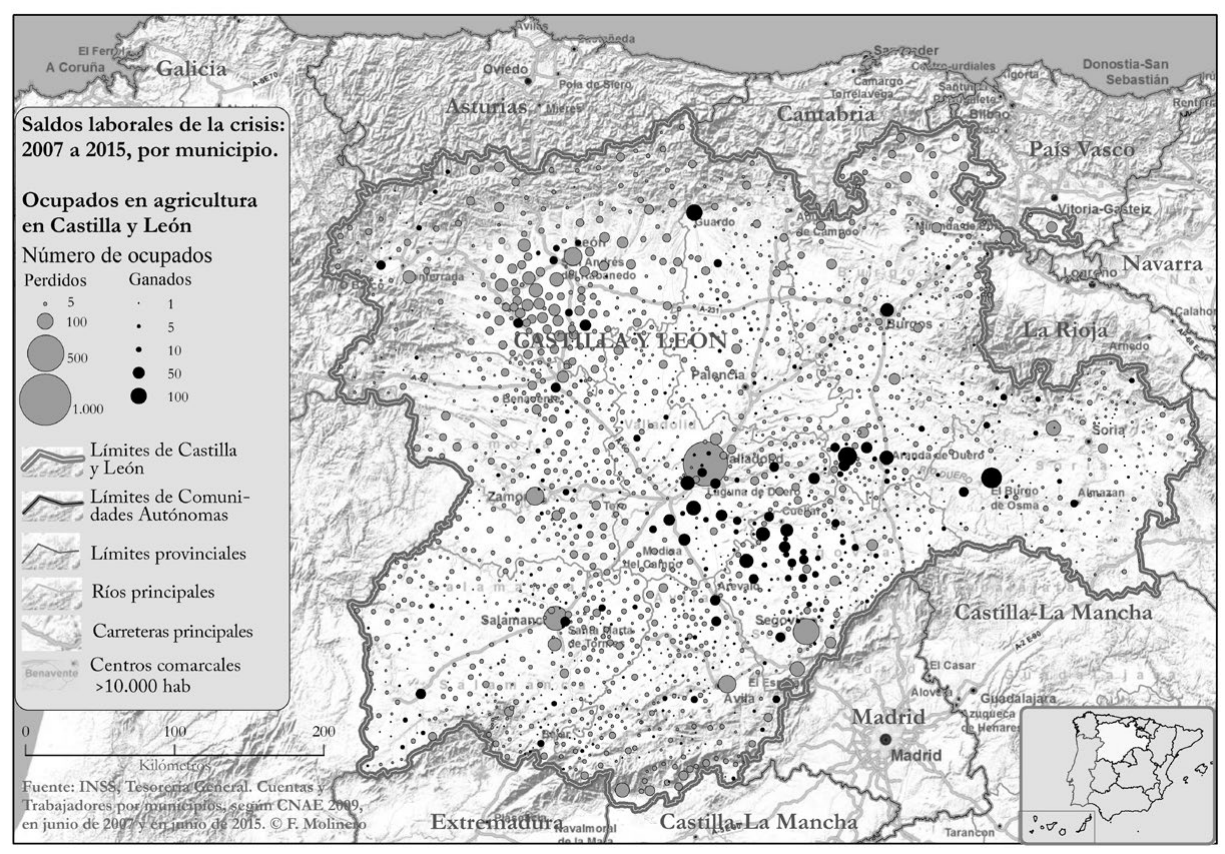

Figura 3. Saldos de ocupados en la agricultura entre 2007 y 2015, por municipio.

han sido superados por otros pocos artesanos y gente dedicada a los servicios de turismo y restauración, quienes dominan sobre los demás (Alario Trigueros et al., 2014: 413). La figura 4 nos muestra las pérdidas demográficas municipales en las que tan solo aparecen unas comarcas dinámicas, coincidentes con el área de influencia de Madrid, algunos ejes en torno a las carreteras principales y en los sectores de agricultura intensiva, además de algunos otros enclaves singulares. Sin embargo, los municipios con más pérdida de población no coinciden con los que más pérdidas agrarias tienen, porque una buena parte de las explotaciones agrarias declara su «sede social» en las capitales de provincia, que, a su vez, son las que más explotaciones «oficiales» pierden, como se observa sobre todo en Valladolid, seguida de Salamanca y Segovia, León, Ávila y Soria.

En el cuadro 3 se ve, por el contrario, que son los municipios más pequeños los que más ocupados agrarios, y explotaciones, pierden, tanto en términos absolutos como relativos, aunque los mayores de $10.000 \mathrm{~h}$ alcanzan casi la media regional, lo que nos habla de una tendencia general hacia la concentración del poblamiento, según la cual los agricultores prefieren vivir en los centros comarcales, o en las ciudades, y desplazarse a trabajar a los pueblos donde tienen la explotación. Es muy claro en Soria capital, pero también en Ciudad Rodrigo, en Aguilar de Campóo, o en Arévalo... y en todos los núcleos de entre 5 y 10 


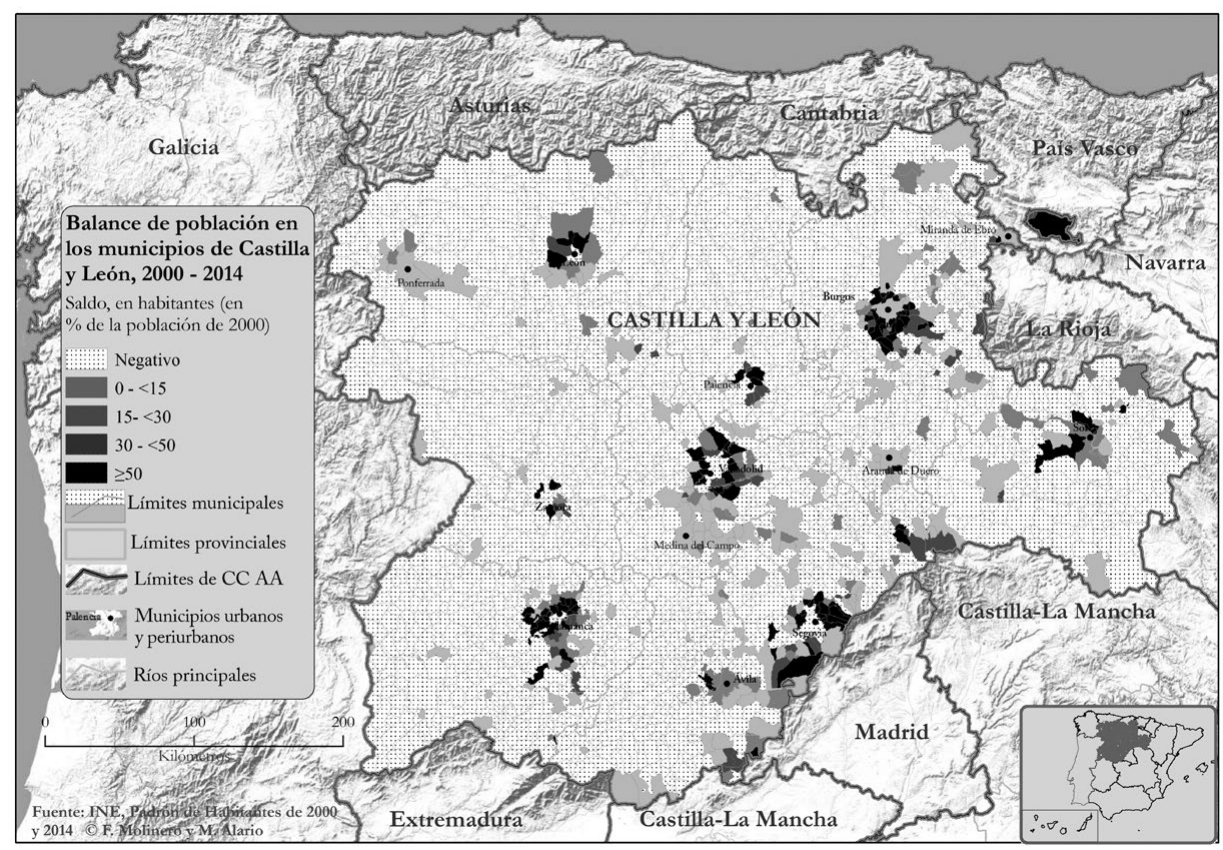

Figura 4. Saldos de población en los municipios de Castilla y León 2000-2014.

mil habitantes, pues estos ganan casi un 5\% de empleo agrario durante los años de la crisis. No obstante, y aunque esa tendencia a la concentración es clara, no es capaz de oscurecer el hecho de que la mayoría de los agricultores vive en municipios pequeños, pues los de menos de mil habitantes, que suman casi 2.000 , dan cobijo al 58\% de los empleados en la agricultura, mientras los 23 municipios más grandes tan solo albergan al 13,5\%.

La dinámica de estos hechos se basa en una pérdida general de agricultores en todo tipo de municipio excepto en los centros comarcales (5.000 a 10.000 $\mathrm{h}$ ), que son los únicos que ganan, frente a los más pequeños $(<500 \mathrm{~h})$, que son los que más ocupados agrarios pierden en cifras absolutas y relativas; las ciudades también pierden, pero, al ser muy poco numerosas, apenas inciden en el conjunto, por más que su tasa de pérdidas no alcance la media regional. De este modo, podemos concluir que la tendencia a la concentración de los agricultores en los centros comarcales y de servicios es creciente, pero aún de poco valor, porque el grueso de empleados agrarios vive en los municipios menores de $2.000 \mathrm{~h}$. Sin embargo, si comparamos los datos de empleo agrario con los de población general, comprobamos que siguen la misma dinámica, pues son también los municipios menores de mil habitantes los que más población pierden, superando los 101.000 h en el lapso considerado (2000 a 2014; cfr. cuadro 3), 
Cuadro 3. Saldo de ocupados agrarios entre 2007 y 2015, por tamaño de municipio, en Castilla y León

\begin{tabular}{|c|c|c|c|c|c|c|c|c|c|}
\hline 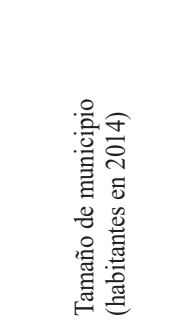 & 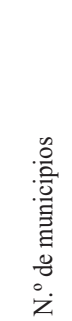 & 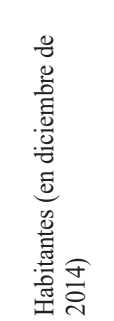 & 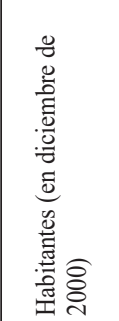 & 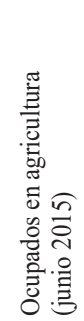 & 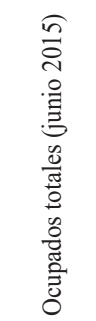 & 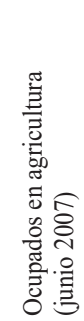 & 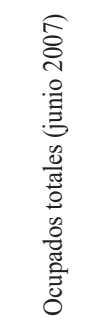 & 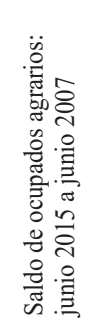 & 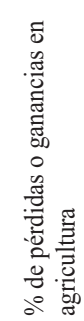 \\
\hline$<500$ & 1.747 & 298.131 & 378.460 & 25.379 & 68.191 & 31.495 & 76.240 & -6.116 & $-19,42$ \\
\hline$\geq 500 \mathrm{a}<1.000$ & 239 & 164.420 & 185.324 & 9.782 & 40.795 & 11.936 & 45.808 & -2.154 & $-18,05$ \\
\hline$\geq 1.000 \mathrm{a}<2.000$ & 134 & 183.876 & 184.655 & 7.585 & 54.140 & 8.792 & 60.077 & -1.207 & $-13,73$ \\
\hline$\geq 2.000 \mathrm{a}<5.000$ & 70 & 217.658 & 187.205 & 5.090 & 62.259 & 5.376 & 71.952 & -286 & $-5,32$ \\
\hline$\geq 5.000 \mathrm{a}<10.000$ & 35 & 240.164 & 200.939 & 4.604 & 79.387 & 4.390 & 88.075 & 214 & 4,87 \\
\hline$>10.000$ & 23 & 1.390 .541 & 1.342 .165 & 8.197 & 551.755 & 9.567 & 628.918 & -1.370 & $-14,32$ \\
\hline TOTALES & 2.248 & 2.494 .790 & 2.478 .748 & 60.637 & 856.527 & 71.556 & 971.070 & -10.919 & $-15,26$ \\
\hline
\end{tabular}

Fuente: INE, Padrón de Habitantes 2014; INSS: Tesorería General: Cuentas y Trabajadores por municipio, clasificados según la CNAE 09 a dos dígitos, en junio de 2007 y en junio de 2015.

mientras los del umbral superior ( 1.000 a 2.000 h) todavía continúan perdiendo algún habitante, en tanto que todos los que superan los dos mil habitantes ganan población. Estos hechos obedecen claramente a la dinámica de una región del rural profundo de Europa, que, además, pierde más población por su carácter agrario y por que la agricultura no deja de modernizarse y adecuarse a las exigencias del mercado global.

\section{Modernización imparable y estructuras resultantes}

La evolución rápida de las estructuras agrarias de Castilla y León y su inserción en el mercado global obedecen al conjunto de factores que hemos analizado. En primer lugar, la presión del mercado, que obliga a retirarse a los menos eficientes. En segundo lugar, las ayudas PAC, que representan un seguro agrario y que permiten a los agricultores tecnificarse, incluso por encima de sus necesidades. En tercer lugar, el envejecimiento general y el abandono por consunción biológica. Estos tres vértices del triángulo están empujando hacia un futuro en el que el campo de Castilla y León se prevé más empequeñecido, menos denso todavía, más especializado y más competitivo. La regresión demográfica que le afecta es clara: basta echar un vistazo al mapa-figura 4. La pérdida de activos es evidente: en junio de 2015 no había más que 60.637 cotizantes a la Seguridad Social en agricultura, lo que representa un $7 \%$ de los cotizantes totales. El envejecimiento 
es nítido: Castilla y León tiene un índice de Envejecimiento de 185 (en 2015), solo superado por Galicia y Asturias (INE, 2015, web), frente a una media de 115 en España, pero que alcanza cotas de 700 en numerosos municipios rurales, donde los mayores de 65 años predominan abrumadoramente, frente a la nimia representación de los menores de 15 años.

Producto de esta situación, evolución y estructuras, las explotaciones agrarias están por debajo de las que registra el último censo agrario de 2009. Así, la Encuesta de Explotaciones Agrícolas de 2013 da para Castilla y León una cifra de 90.610, aunque más de la mitad no alcanzan las 20 ha, hecho que nos habla ya de explotaciones complementarias, a Tiempo Parcial, o que simplemente se mantienen para ir cobrando las ayudas de la PAC. Por ello, conviene comparar estos resúmenes con los pagos PAC del FEGA (para 2014), para analizar su significado y obtener las conclusiones pertinentes. De todos modos, el cuadro 4 permite ver que las mayores de 50 hectáreas controlan casi el $83 \%$ de la superficie total, lo que nos indica que son estas explotaciones, de carácter extensivo, con cerca de 200 ha de superficie media, las absolutamente predominantes y las que dan personalidad a la región; se dedican a los «productos continentales», es decir, a cereales y forrajes, aunque incrementan su capacidad merced al regadío y a la combinación con otros esquilmos.

La comparación con las ayudas PAC resulta bien expresiva, pues si las de menos de 20 ha suponen la mitad de las explotaciones, también vemos que la mitad $(49 \%)$ de los perceptores de ayudas está por debajo de $5.000 €$ (cuadro 5 y figura 5), que es un umbral de explotación marginal o complementaria.

De entrada, a los casi 105.000 perceptores de ayuda de este último año, hay que restarle todos aquellos que reciben menos de $1.250 €$, que ya aparecen sin

Cuadro 4. Estructura de las explotaciones agrarias en Castilla y León, 2013

\begin{tabular}{|l|r|r|r|r|r|r|}
\hline & $\begin{array}{c}\text { Explota- } \\
\text { ciones. N. }\end{array}$ & $\begin{array}{c}\text { Explota- } \\
\text { ciones. \% }\end{array}$ & $\begin{array}{c}\text { Superficie } \\
\text { total. Ha. }\end{array}$ & $\begin{array}{c}\text { Superficie } \\
\text { total.\% }\end{array}$ & SAU. Ha. & SAU. \% \\
\hline Explotaciones con tierras & 90.610 & 100 & 6.502 .199 & 100 & 5.295 .684 & 100 \\
\hline Explotaciones sin SAU & 698 & 0,77 & 8.553 & 0,13 & 0 & 0 \\
\hline Explotaciones con SAU & 89.912 & 99,23 & 6.493 .646 & 99,87 & 5.295 .684 & 100 \\
\hline$<1$ & 1.573 & 1,74 & 13.839 & 0,21 & 824 & 0,02 \\
\hline $1 \mathrm{a}<2$ & 8.348 & 9,21 & 42.186 & 0,65 & 11.267 & 0,21 \\
\hline $2 \mathrm{a}<5$ & 12.040 & 13,29 & 47.916 & 0,74 & 37.599 & 0,71 \\
\hline $5 \mathrm{a}<10$ & 9.037 & 9,97 & 76.900 & 1,18 & 64.194 & 1,21 \\
\hline $10 \mathrm{a}<20$ & 10.815 & 11,94 & 168.462 & 2,59 & 152.254 & 2,88 \\
\hline $20 \mathrm{a}<30$ & 8.106 & 8,95 & 226.014 & 3,48 & 199.710 & 3,77 \\
\hline $30 \mathrm{a}<50$ & 12.084 & 13,34 & 524.529 & 8,07 & 464.275 & 8,77 \\
\hline $50 \mathrm{a}<100$ & 13.084 & 14,44 & 1.151 .812 & 17,71 & 937.853 & 17,71 \\
\hline $\mathrm{B}=100$ & 14.825 & 16,36 & 4.241 .987 & 65,24 & 3.427 .707 & 64,73 \\
\hline
\end{tabular}

Fuente: INE: Encuesta de las Explotaciones Agrícolas 2013. 
Cuadro 5. Distribución de los pagos PAC en Castilla y León en 2014, por tramos

\begin{tabular}{|l|c|c|c|c|c|c|c|}
\hline Tramos en $€$ & $\begin{array}{c}\text { N. }{ }^{.} \text {de } \\
\text { perceptores }\end{array}$ & $\begin{array}{c}\text { \% de } \\
\text { perceptores }\end{array}$ & $\begin{array}{c}\text { Pagos } \\
\text { totales. } \\
\text { Millones } €\end{array}$ & $\begin{array}{c}\text { \% de pagos } \\
\text { totales }\end{array}$ & $\begin{array}{c}\text { Pago Único. } \\
\text { Millones } €\end{array}$ & $\begin{array}{c}\text { Otros } \\
\text { pagos. } \\
\text { Millones } €\end{array}$ & $\begin{array}{c}\text { \% de pago } \\
\text { único sobre } \\
\text { pagos } \\
\text { totales }\end{array}$ \\
\hline$<1.250$ & 20.448 & 23,1 & 11,405 & 1,1 & 9,677 & 1,727 & 84,9 \\
\hline 1.250 a 2.500 & 10.437 & 11,8 & 18,815 & 1,9 & 15,576 & 3,239 & 82,8 \\
\hline 2.500 a 5.000 & 12.267 & 13,9 & 44,882 & 4,4 & 39,445 & 5,437 & 87,9 \\
\hline 5.000 a 10.000 & 14.622 & 16,6 & 105,746 & 10,5 & 89,885 & 15,861 & 85,0 \\
\hline 10.000 a $<15.000$ & 9.383 & 10,6 & 116,213 & 11,5 & 87,548 & 28,664 & 75,3 \\
\hline 15.000 a $<20.000$ & 6.046 & 6,8 & 104,886 & 10,4 & 84,304 & 20,582 & 80,4 \\
\hline 20.000 a $<30.000$ & 7.088 & 8,0 & 172,915 & 17,1 & 134,019 & 38,896 & 77,5 \\
\hline 30.000 a $<50.000$ & 5.399 & 6,1 & 204,051 & 20,2 & 151,114 & 52,938 & 74,1 \\
\hline 50.000 a $<100.000$ & 2.179 & 2,5 & 143,050 & 14,1 & 95,731 & 47,319 & 66,9 \\
\hline 100.000 a $<300.000$ & 431 & 0,5 & 60,108 & 5,9 & 34,161 & 25,947 & 56,8 \\
\hline 300.000 y más & 37 & 0,0 & 29,360 & 2,9 & 5,240 & 24,119 & 17,8 \\
\hline Total general & $\mathbf{8 8 . 3 3 7}$ & $\mathbf{1 0 0 , 0}$ & $\mathbf{1 . 0 1 1}$ & $\mathbf{1 0 0 , 0}$ & $\mathbf{7 4 7}$ & $\mathbf{2 6 5}$ & $\mathbf{7 3 , 8}$ \\
\hline
\end{tabular}

Fuente: FEGA: Pagos PAC 2014, Castilla y León (www.fega.es, Consulta noviembre 2015).

identificación personal, pero que suman un total de 20.000 y no cobran más que el $1,1 \%$ de los pagos totales. En segundo lugar, habría que restar otro conjunto de entre 1.250 y $2.500 €$, que representan otro $12 \%$ y tan solo cobra un $2 \%$ de los pagos. Finalmente, hay otro grupo de entre 2.500 y $5.000 €$ que, si son agricultores principales, no tardarán en desaparecer como tales. Así, nos aproximamos más a los valores de la Encuesta 2013 que a las hinchadas cifras de perceptores de PAC. Es a partir de los 5.000, y hasta los $100.000 €$, donde se sitúan los agricultores profesionales, generalmente de origen familiar, pero que cada vez evolucionan más hacia empresarios agrarios. Representan algo más de la mitad de las explotaciones y perciben el $84 \%$ de los pagos. Son los verdaderos protagonistas del campo, los que mantienen la agricultura y crean paisaje. $\mathrm{Si}$ referimos estas 45.000 explotaciones a las 90.000 que aparecen censadas en la Encuesta de las explotaciones Agrícolas de 2013, resulta que las verdaderas explotaciones agrarias son justo la mitad. Si las referimos a las 105.000 del Censo Agrario de 2009, nos da una proporción del 43\%. Es la cifra referencial de las explotaciones funcionales de las tierras del Duero. En ese grupo hay una gran diversidad, pero quienes viven de la agricultura principalmente están en ese conjunto, por más que haya un nutrido colectivo de propietarios que apenas producen y venden productos y que se mantienen como meros perceptores de ayudas PAC 


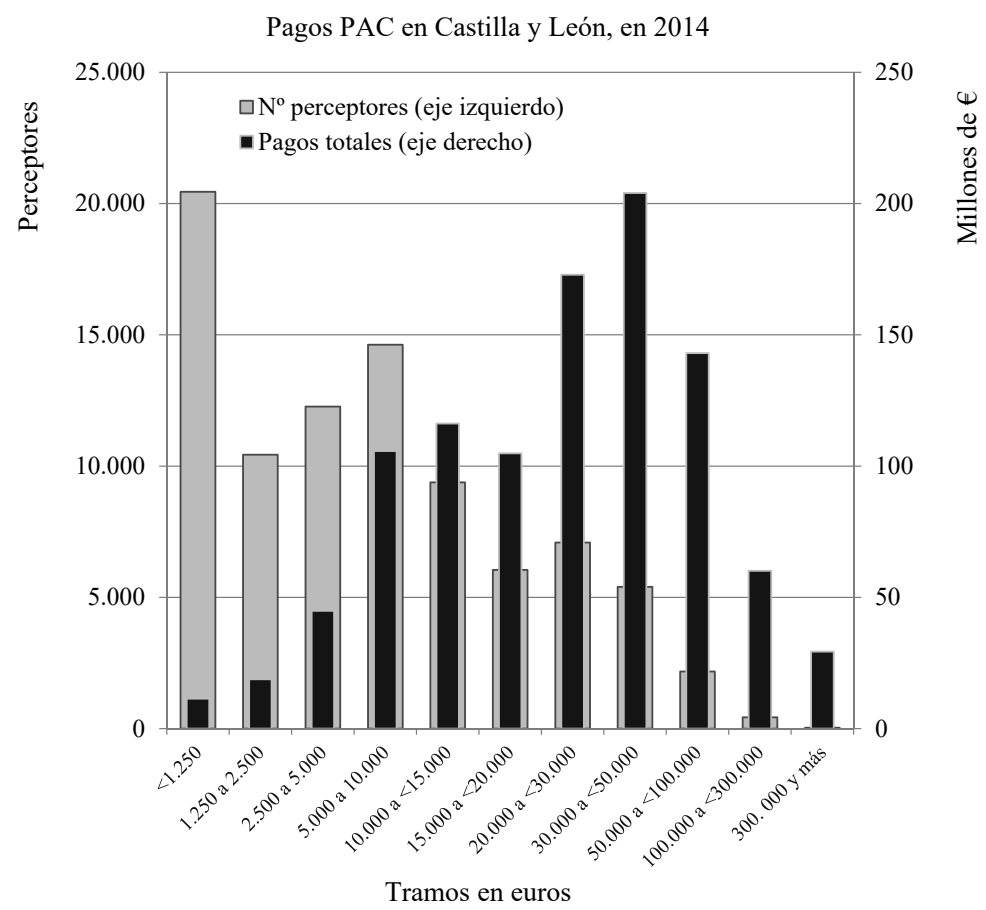

Figura 5. Distribución de los pagos PAC en Castilla y León en 2014, por tramos.

Y fundamentalmente se distribuyen por el ámbito de las llanuras: campiñas, páramos y penillanuras, por cuanto en las montañas, como hemos insistido, cada vez quedan menos ganaderos, aunque también se han modernizado y controlan hatos considerables. Tal como se observa en la figura 6, la distribución municipal de los pagos PAC en 2014, no difiere de la de 2009 (figura 2), por cuanto las estructuras agrarias que generan esos pagos son las mismas, si bien se ha reducido el número de perceptores y ha aumentado la cuantía individual percibida. En efecto, en contra de la mentalidad general, y como el presupuesto de la UE para agricultura está reduciéndose, se piensa que los pagos PAC a los agricultores están disminuyendo, pero esto solo es una cara de la moneda, por cuanto esa situación real, afecta a los marginales, a los propietarios que mantienen la explotación para cobrar la PAC como complemento económico o a otros titulares que pagan la gestión y labores a agricultores profesionales, pero la reducción no les afecta a estos, por cuanto no solo han agrandado su explotación, sino que la han diversificado para hacerse beneficiarios de medidas de desarrollo rural. 


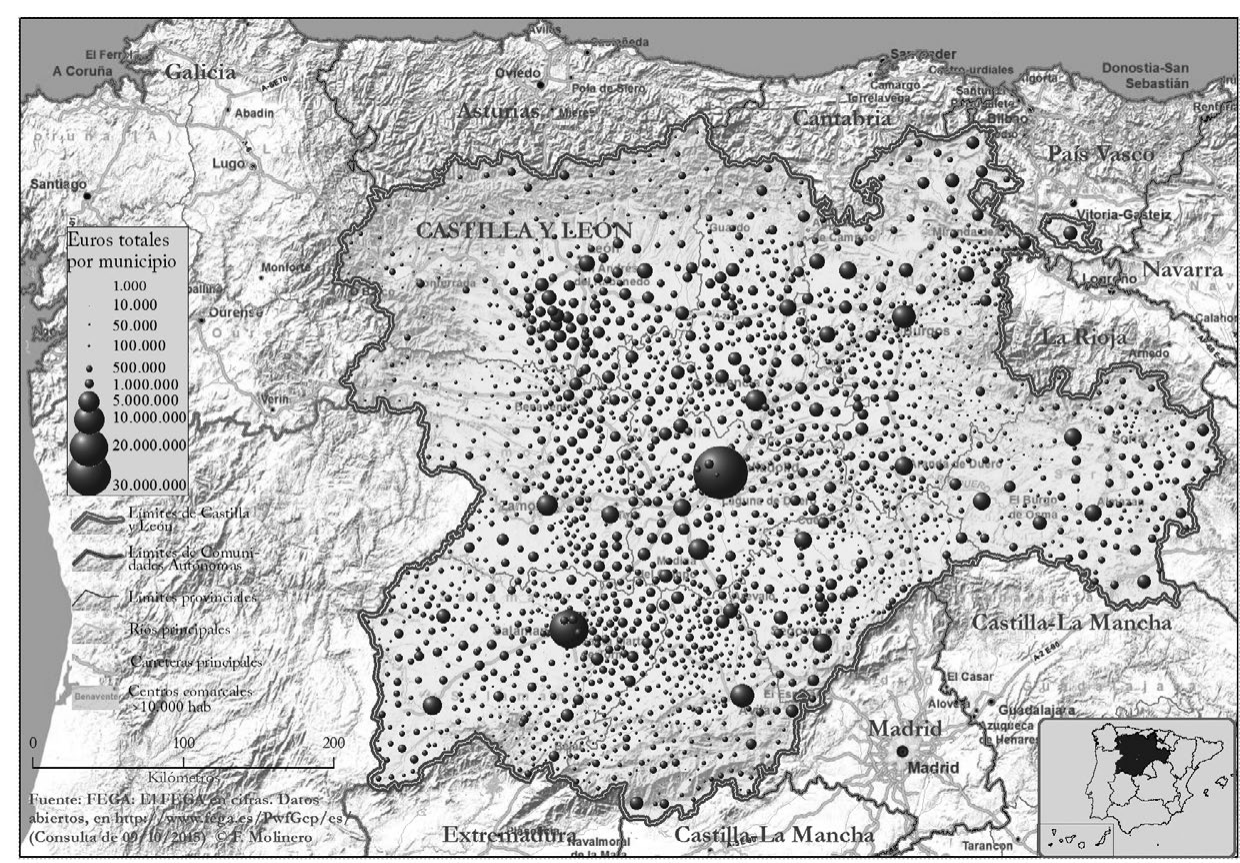

Figura 6. Distribución municipal de los pagos PAC en Castilla y León en 2014.

\section{EXPLOTACIONES AGRARIAS FRENTE A DESARROLLO RURAL EN LOS PAGOS PAC}

La política agraria común europea tiende a restringir las ayudas directas y a sustituirlas por otras relacionadas con el desarrollo rural. Aunque la realidad lo desmiente, no cabe duda que es la dirección decidida y defendida por la Comisión Europea. Tomando como referencia las ayudas que llegaron a Castilla y León en 2009 y en 2014, podemos comprobar que los pagos directos se reducen en conjunto, aunque constituyen las tres cuartas partes de los pagos totales (el 73,8\% en 2014, que totalizan 747 Meuros de pago único); en 2009 se habían transferido 876 millones, sobre un total de 1.180 Meuros (FEGA, Pagos PAC 2009 , cfr. cuadro 2), lo que representa un $74,2 \%$. Esto significa que los pagos directos tienen absoluto predominio sobre el desarrollo rural, por más importancia que se quiera dar a los LEADER y a otras actuaciones.

Ciertamente, la reducción de los pagos directos es una medida incuestionable, pero no tan radical como se predica. Por otro lado, el estrato más alto de perceptores de ayudas ( $>300.000 €)$ es el más beneficiado por los pagos que no van directamente al agricultor, lo que refleja una cierta capacidad de manipulación y de adaptación a las convocatorias de ayudas al desarrollo rural, que a menudo recaen en sociedades o empresas de gran agilidad y versatilidad administrativa (cfr. cuadro 5). 
Al margen de la existencia de cazaprimas, es también incuestionable que los agricultores profesionales se han visto obligados a adoptar prácticas agrarias sostenibles, medidas de reforestación, y otras ayudas al desarrollo rural, integradas en las primas que reciben y que les permiten mantener una base firme de Pagos PAC en su explotación. Como el total de ayudas apenas ha disminuido, y como el número de perceptores sí lo ha hecho, el resultado es un crecimiento de las ayudas por agricultor. Si a ello unimos que el $40 \%$ de perceptores pequeños apenas recibe el $3 \%$ de los fondos, podemos comprender que las primas a los agricultores profesionales son sustanciales y que, en conjunto, representan un tercio de las rentas totales, que es la cifra que se maneja habitualmente para Castilla y León y para el interior de España.

Pero, aunque las medidas al desarrollo rural tiendan a crecer, en detrimento de los pagos únicos, o pagos directos, lo cierto es que, al final, la mayor proporción de estos fondos van a parar a los agricultores, porque son los protagonistas del mundo rural. Hay que distinguir, no obstante, lo que sucede en las áreas de montaña en relación con las de llanura, pues la diversificación funcional ha sido nítida en aquéllas, frente a éstas, que continúan ancladas en la agricultura como rama económica básica. Lo podemos ver en el mapa adjunto (figura 7) y en el cuadro 6 y figura 8 , donde se puede comprobar que una buena parte de

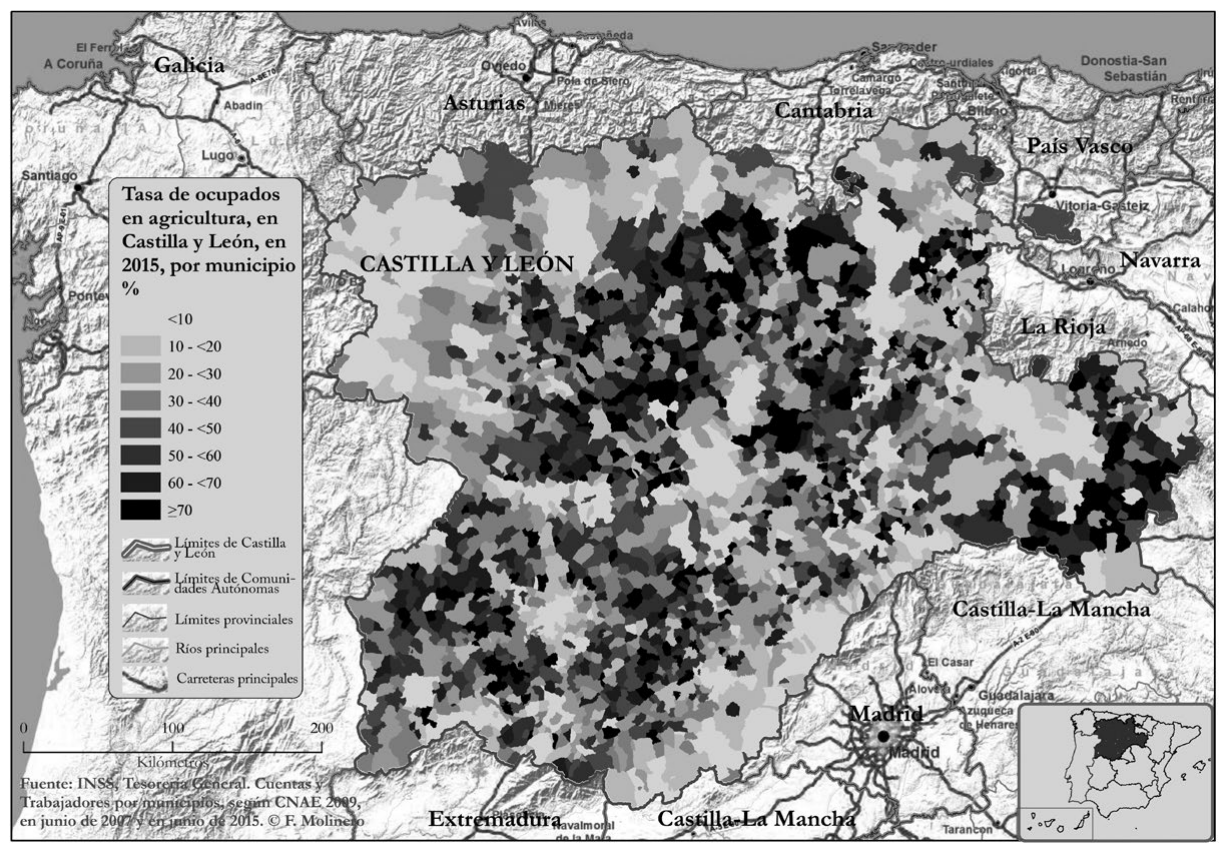

Figura 7. Distribución municipal de los ocupados en agricultura sobre los ocupados totales, en junio de 2015. 


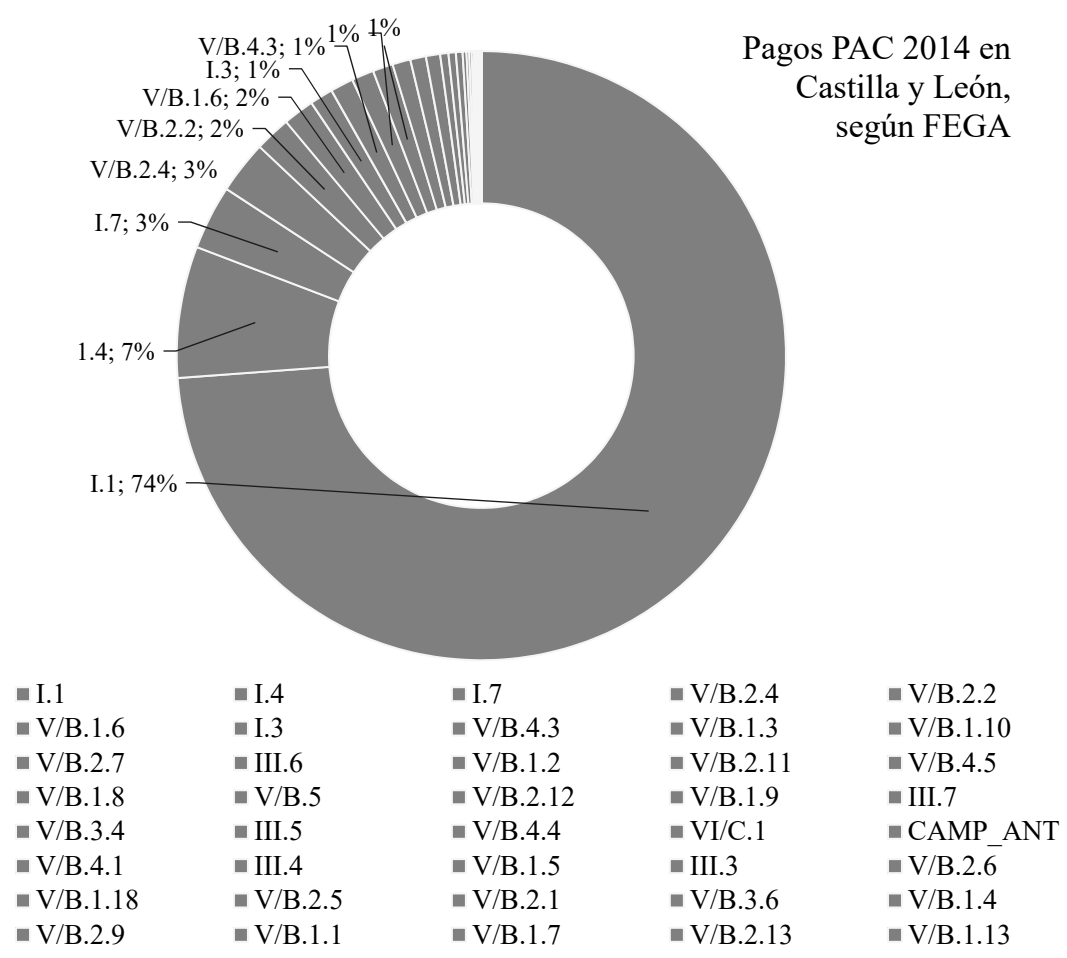

Figura 8. Distribución de los Pagos PAC en 2014 en Castilla y León, ordenado por el monto total de cada medida (véanse códigos y cuantías en el cuadro 6).

los fondos destinados al desarrollo rural acaban en ayudas al desarrollo agrario, en cierto modo, porque no se pueden discriminar en estos ámbitos del rural profundo donde la actividad agraria lo es todo, principalmente en los pueblos más pequeños.

Por si hubiera dudas, los datos del FEGA lo corroboran. En el cuadro 6 se exponen todas las medidas de pagos directos y de desarrollo rural, ordenadas por código de medida, pero en el gráfico (figura 8) están ordenadas por el monto de cada medida. La primera de todas corresponde al Pago Único (medida I.1), que acapara el $74 \%$ del total de pagos. Le sigue, con un 7\%, los pagos por ganado vacuno; mientras las ayudas específicas se sitúan en tercer lugar, con un 3\%; se otorgan a determinados productos o colectivos, para superar situaciones concretas difíciles. Finalmente, las ayudas agroambientales reciben otro 3\%. Estas últimas están a caballo entre el desarrollo agrario y el rural; en conjunto, estas cuatro medidas acaparan el $87 \%$ de los pagos PAC. Es más, hay numerosas medidas que se proponen como medidas de desarrollo rural y van dirigidas claramente 
al desarrollo agrario, como las destinadas a la mejora de la explotación agrícola y otras muchas (véase cuadro 6). Podemos concluir que en las áreas del rural profundo el desarrollo agrario y el rural corren parejos y, por más que en determinadas áreas de la montaña Cantábrica, y en la Sanabria zamorana se haya consolidado un turismo rural de cierto valor, acompañado de algunas actividades de artesanía, ha sido en el área de influencia de Madrid y en algunos otros ejes viarios donde la diversificación económica ha ganado importancia, mientras en las llanuras centrales continúa siendo hegemónica la explotación agraria.

Cuadro 6. Pagos PAC 2014 en Castilla y León, por tipo de medida

\begin{tabular}{|c|c|c|}
\hline Código de medida & Euros & $\begin{array}{c}N .^{\circ} \text { de } \\
\text { beneficiarios* }\end{array}$ \\
\hline I.1 Régimen de pago único & $746.700 .876,9$ & 82.448 \\
\hline $\begin{array}{l}\text { I.3 Ayuda a los productores de remolacha azucarera y caña } \\
\text { de azúcar }\end{array}$ & $12.487 .138,3$ & 4.431 \\
\hline I.4 Pagos por ganado vacuno & $70.556 .300,9$ & 8.462 \\
\hline I.7 Ayuda específica & $34.565 .380,9$ & 20.107 \\
\hline $\begin{array}{l}\text { III.3 Programas de consumo de frutas y hortalizas en las } \\
\text { escuelas }\end{array}$ & $142.229,9$ & 4 \\
\hline III.4 Programa de consumo de leche en las escuelas & $238.882,5$ & 5 \\
\hline III.5 Ayuda en el sector de las frutas y hortalizas & $761.193,8$ & 9 \\
\hline III.6 Programas de apoyo en el sector vitivinícola & $8.400 .995,5$ & 416 \\
\hline III.7 Ayuda en el sector apícola & $1.180 .083,9$ & 241 \\
\hline $\begin{array}{l}\text { V/B.1.1 Acciones relativas a la información y la } \\
\text { formación profesional [Med.111] }\end{array}$ & $4.661,9$ & 3 \\
\hline $\begin{array}{l}\text { V/B.1.10 Infraestructuras relacionadas con el desarrollo } \\
\text { y la adaptación de la agricultura y de la silvicultura } \\
\text { [Med.125] }\end{array}$ & $10.820 .625,3$ & 2 \\
\hline $\begin{array}{l}\text { V/B.1.13 Participación de los agricultores en programas } \\
\text { relativos a la calidad de los alimentos [Med.132] }\end{array}$ & $3.897,2$ & 14 \\
\hline $\begin{array}{l}\text { V/B.1.18 Explotaciones en proceso de reestructuración } \\
\text { con motivo de la reforma de una organización común de } \\
\text { mercado [Med.144] }\end{array}$ & $44.051,1$ & 35 \\
\hline V/B.1.2 Instalación de jóvenes agricultores [Med.112] & $7.622 .408,8$ & 249 \\
\hline V/B.1.3 Jubilación anticipada [Med.113] & $11.960 .804,9$ & 1.653 \\
\hline $\begin{array}{l}\text { V/B.1.4 Utilización de servicios de asesoramiento } \\
\text { [Med.114] }\end{array}$ & $11.171,5$ & 28 \\
\hline $\begin{array}{l}\text { V/B.1.5 Implantación de servicios de gestión, sustitución } \\
\text { y asesoramiento [Med.115] }\end{array}$ & $164.288,8$ & 17 \\
\hline $\begin{array}{l}\text { V/B.1.6 Modernización de explotaciones agrícolas } \\
\text { [Med.121] }\end{array}$ & 16.713.361,3 & 577 \\
\hline $\begin{array}{l}\text { V/B.1.7 Aumento del valor económico de los bosques } \\
\text { [Med.122] }\end{array}$ & $4.150,9$ & 4 \\
\hline $\begin{array}{l}\text { V/B.1.8 Aumento del valor añadido de los productos } \\
\text { agrícolas y forestales [Med.123] }\end{array}$ & $3.593 .179,8$ & 27 \\
\hline
\end{tabular}




\begin{tabular}{|c|c|c|}
\hline $\begin{array}{l}\text { V/B.1.9 Cooperación para el desarrollo de nuevos } \\
\text { productos, procesos y tecnologías en el sector agrícola y } \\
\text { alimentario y en el sector forestal [Med.124] }\end{array}$ & $1.342 .084,1$ & 2 \\
\hline $\begin{array}{l}\text { V/B.2.1 Ayudas destinadas a indemnizar a los agricultores } \\
\text { por las dificultades naturales en zonas de montaña } \\
\text { [Med.211] }\end{array}$ & $21.554,8$ & 32 \\
\hline V/B.2.11 Ayudas en favor del medio forestal [Med.225] & $4.460 .784,4$ & 472 \\
\hline $\begin{array}{l}\text { V/B.2.12 Recuperación del potencial forestal e } \\
\text { implantación de medidas preventivas [Med.226] }\end{array}$ & $1.458 .735,8$ & 170 \\
\hline V/B.2.13 Inversiones no productivas [Med.227] & $4.092,3$ & 1 \\
\hline $\begin{array}{l}\text { V/B.2.2 Ayudas destinadas a indemnizar a los agricultores } \\
\text { por las dificultades en zonas distintas de las de montaña } \\
\text { [Med.212] }\end{array}$ & 19.248.300,1 & 14.784 \\
\hline V/B.2.4 Ayudas agroambientales [Med.214] & $28.388 .418,3$ & 5.183 \\
\hline $\begin{array}{l}\text { V/B.2.5 Ayudas relativas al bienestar de los animales } \\
\text { [Med.215] }\end{array}$ & $23.870,5$ & 8 \\
\hline V/B.2.6 Inversiones no productivas [Med.216] & $78.026,4$ & 5 \\
\hline $\begin{array}{l}\text { V/B.2.7 Primera forestación de tierras agrícolas } \\
\text { [Med.221] }\end{array}$ & $9.696 .192,4$ & 3.505 \\
\hline $\begin{array}{l}\text { V/B.2.9 Primera forestación de tierras no agrícolas } \\
\text { [Med.223] }\end{array}$ & $8.484,0$ & 1 \\
\hline $\begin{array}{l}\text { V/B.3.4 Servicios básicos para la economía y la población } \\
\text { rural [Med.321] }\end{array}$ & $786.604,7$ & 1 \\
\hline $\begin{array}{l}\text { V/B.3.6 Conservación y mejora del patrimonio rural } \\
\text { [Med.323] }\end{array}$ & $13.743,2$ & 1 \\
\hline $\begin{array}{l}\text { V/B.4.1 Aplicación de estrategias de desarrollo local. } \\
\text { Competitividad [Med.411] }\end{array}$ & $275.916,9$ & 12 \\
\hline $\begin{array}{l}\text { V/B.4.3 Aplicación de estrategias de desarrollo local. } \\
\text { Calidad de vida/diversificación [Med.413] }\end{array}$ & 12.368.731,7 & 333 \\
\hline $\begin{array}{l}\text { V/B.4.4 Ejecución de proyectos de cooperación } \\
{[\text { Med.421] }}\end{array}$ & $524.814,8$ & 8 \\
\hline $\begin{array}{l}\text { V/B.4.5 Funcionamiento del grupo de acción local, } \\
\text { adquisición de capacidades y promoción del territorio } \\
\text { [Med.431] }\end{array}$ & $3.890 .806,9$ & 41 \\
\hline V/B.5 Asistencia Técnica [Med.511] & $2.066 .676,1$ & 1 \\
\hline VI/C.1 POSEI & $398.808,1$ & 7 \\
\hline $\begin{array}{l}\text { CAMP_ANT Medidas de campañas anteriores } \\
\text { correspondientes a regímenes de ayuda que no están en } \\
\text { vigor }\end{array}$ & $398.590,8$ & 22 \\
\hline Total general & $1.011 .430 .920,0$ & 143.321 \\
\hline
\end{tabular}

* El número de beneficiarios es muy superior al de perceptores de Pago Único, porque hay muchas personas físicas y jurídicas que reciben ayudas de varias medidas a la vez.

Fuente: FEGA: Pagos PAC 2014 ¿Quién recibe los pagos de la PAC?, en http://www.fega.es/ PwfGcp/es/accesos_directos/datos_abiertos/index.jsp (Consulta de octubre 2015) 


\section{CONCLUSIÓN}

El análisis de las estructuras agrarias de Castilla y León abunda en la idea de que la función agrícola y ganadera sigue siendo el pilar fundamental que sostiene un espacio rural vastísimo, seriamente aquejado por los problemas de despoblación y envejecimiento. La multifuncionalidad se dibuja tímidamente de la mano de nuevas actividades industriales, energéticas, turísticas..., que singularizan, por lo novedoso de sus experiencias, ciertas áreas que aprovechan las rentas de situación, la presencia de recursos o el impulso de voluntades emprendedoras. Pero la agricultura y la ganadería, con un perfil dinámico y empresarial, sigue siendo la vía de integración de estos espacios en la economía moderna. En su extensa orla montañosa, mayoritaria y prematuramente despoblada, una actividad ganadera extensiva comparte activos con las nuevas empresas orientadas a satisfacer la demanda de ocio de una sociedad urbana que ahora valora sus recursos paisajísticos y patrimoniales (naturaleza, cultura...). En las llanuras, aferradas a una agricultura moderna, tecnificada y dinámica, con explotaciones de entre 200 y 300 ha, viven, con cierto grado de acomodo, unos jóvenes agricultores cada vez más mermados en número como para dar alternativas al desarrollo agrario. En este sentido, la explotación agrícola, extensiva, cerealista e incapaz de emplear mano de obra, ha triunfado. Frente a ella, las explotaciones del regadío y de la viticultura están introduciendo nuevas perspectivas, pero el paisaje agrario y humano dominante es el de los vastos horizontes agrícolas, productivos y competitivos, pero cada vez más vacíos.

\section{BIBLIOGRAFÍA}

Alario Trigueros, M.; Molinero Hernando, F.; Morales Prieto, E. (2014): «Nuevos usos residenciales en el espacio rural de Castilla y León». Boletín de la Asociación de Geógrafos Españoles, n. ${ }^{\circ}$ 66, pp. 397-422.

Alario Trigueros, M. (2004): «Diversificación económica en el medio rural: el turismo rural», en Molinero Hernando, F.; Majoral Moliné, R.; García Bartolomé, J.M. y García Fernández, G. (coords.): Atlas de la España Rural. Madrid, Ministerio de Agricultura Pesca y Alimentación, pp. 355 a 363.

Alario, M. y BARAJA, E. (2006): «Políticas públicas de desarrollo rural en Castilla y León, ¿sostenibilidad consciente o falta de opciones?: LEADER II». Boletín de la Asociación de Geógrafos Españoles, n. ${ }^{\circ}$ 41, pp. 267-293.

Baraja, E.; Molinero, F.; Herrero, D. (2014): «Estructuras agrarias en la provincia de León: veinte años de evolución», en Cortizo, J.; Redondo, J. M.; SÁnchez, M. J. (coords.): De la Geografía rural al desarrollo local. Homenaje a Antonio Maya Frades. León, Universidad de León, Área de Publicaciones, pp. 337-351.

Barrio Aliste, J. M. del (2009 y 2010): La población de Castilla y León en los inicios del siglo XXI. Valladolid, Fundación Perspectivas de Castilla y León y Caja España (Obra Social), Informe 1/2009, en http://quedateavivir.files.wordpress.com/2010/02/ 
informe-1-2009-revision-31.pdf, 200 pp. Informe 2/2010, Actualización 2010, 13 pp., disponible en http://www.leonoticias.com/adjuntos/fichero_38642_20100527. pdf

Camarero, L. (coord.), Cruz, F.; González, M.; del Pino, J. A.; Oliva, J. y Sampedro, R. (2009): La población rural de España. De los desequilibrios a la sostenibilidad social. Barcelona, Obra social Fundación «la Caixa». Disponible en www.laCaixa. es/ObraSocial/

Collantes, F. y Pinilla, V. (2011): «Peaceful Surrender. The depopulation of Rural Spain in the Twentieth Century (Cambridge Scholar Publishing», 202 pp.

Consejo Económico y Social de Castilla y León (2012): Población y Poblamiento en Castilla y León: 1950-2010, coordinado por J. M. Delgado. Valladolid, Junta de Castilla y León, $1.026 \mathrm{pp}$.

Delgado Urrecho, J. M. y Caballero Fernández-Rufete, P. (coords.) (2005): La situación de los nuevos yacimientos de empleo en Castilla y León. Valladolid, Consejo Económico y Social de Castilla y León, pp. 361-344.

Fega (2015); Pagos PAC 2014 ¿Quién recibe los pagos de la PAC?, en http://www. fega.es/PwfGcp/es/accesos_directos/datos_abiertos/index.jsp (Consulta de octubre 2015)

García SANZ, B. (2003): La sociedad rural de Castilla y León ante el próximo siglo. Junta de Castilla y León. Consejería de Cultura y Turismo, 417 pp.

GARCía SANZ, B. (2011): Ruralidad emergente, posibilidades y retos. Madrid, MARM, $538 \mathrm{pp}$.

INE (2015): http://www.ine.es/jaxiT3/Datos.htm?t=1452 Índices de Envejecimiento por CCAa (Consulta de 11/11/2015).

Maté, V. (2015): «El campo se abre al mercado», en el País, domingo 25 de octubre de 2015, Negocios, p. 36.

Molinero Hernando, F. (2010): «Las áreas rurales del interior de España frente al cuarto paradigma de desarrollo rural», en MAYol, J., MunTANer, L. y Rullán, O. (eds.): Homenatge a Bartomeu Barceló I Pons, gèograf. Palma de Mallorca, Muntaner, 810 pp., cfr. pp.441-457.

Molinero, F.; Herrero, D.; Baraja, E. (2012): «Significado y valor de los pagos «PAC» para el estudio de las estructuras agrarias en Castilla y León». Nimbus, n. ${ }^{\circ}$ 29-30, pp. 431-446.

Molinero Hernando, F. (2012) «Las intensas transformaciones del mundo rural castellano-leonés: la marcha hacia el cuarto paradigma de desarrollo rural», en CESCyL: Población y Poblamiento en Castilla y León, coordinado por J.M. Delgado URRECHO. Consejo Económico y Social de Castilla y León, Valladolid, 805 pp., cfr. pp. 385-457.

Monreal-Bosch, P.; Gifre, M. y Valle, A. Del (2013): «Envejeciendo en un mundo cambiante. El entorno rural una nueva realidad social. Aging in a changing world. Rural context a new social reality». Athenea Digital - 13(2), pp. 47-63.

Morales Prieto, E. (2011): «Las políticas de desarrollo rural como mecanismos de actuación para el aprovechamiento de los recursos endógenos y asentamiento de 
población. Los casos de Tierra de Campos y Torozos». Actas del VIII Coloquio de Desarrollo Local, Baeza,15 pp.

Nogué I Font, J. (1988): «El fenómeno neorrural». Agricultura y sociedad, n. ${ }^{\circ}$ 47, pp. 145-175.

Palacios, R. y González, A. (2013): Bienvenid@al campo. Experiencias y oportunidades en el mundo rural. Logroño, $154 \mathrm{pp}$.

SAmpedro Gallego, R. (2011): «El asentamiento de inmigrantes extranjeros en el medio rural de Castilla y León: pautas territoriales y lógicas sociales». Comunicación a Congreso, disponible en http://www.fes-web.org/uploads/files/modules/congress/11/papers/2067.pdf

\section{Agradecimientos}

Trabajo elaborado con el apoyo del Proyecto I+D+i, de Ref. CSO201239564-C07-01, sobre Paisajes patrimoniales de la España interior septentrional y occidental, financiado por el MINECO. 